\title{
Diensthabende
}

\section{Ruhig Blut!}

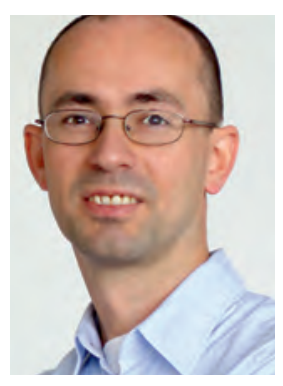

Sechs Jahre. Wow! Eine lange Zeit. Eigentlich könnte man meinen, das müsste reichen, um aus jungen motivierten Menschen fertige Ärzte zu machen. Doch spätestens, wenn das PJ naht, bekommen viele Muffensausen: Bin ich tatsächlich darauf vorbereitet, alleine Patienten zu versorgen? Was muss ich noch lernen, um beim Klinikeinstieg nicht auf die Nase zu fallen? Um darauf eine Antwort zu geben, haben wir mit erfahrenen Klinikärzten gesprochen (S. 26). Ein Zitat eines Chefarztes: „Assistenzärzte müssen zum Einstieg ein gewisses allgemeinmedizinisches Wissen haben. Aber können müssen sie im Prinzip nichts." Ganz so leger sahen das unsere übrigen Gesprächspartner zwar nicht - aber trotzdem lautet das Fazit: Ruhig Blut! Wenn man sich im 9. Semester noch nicht zutraut, eine Station managen zu können, ist das kein Zeichen dafür, dass man zu versagen droht. Es ist schlichtweg normal! Also: Sechs Jahre dauert ein Medizinstudium. Nutzt diese lange Zeit ... Ja, wozu? Nein, nicht nur um zu pauken. Bausteine für eine gute Karriere zu finden: den Spaß an diesem Job - und die fachliche Nische, wo man ihn am besten leben kann. In diesem Heft findet ihr dazu ein paar Vorschläge.

Herzlichst, euer Dieter Schmid

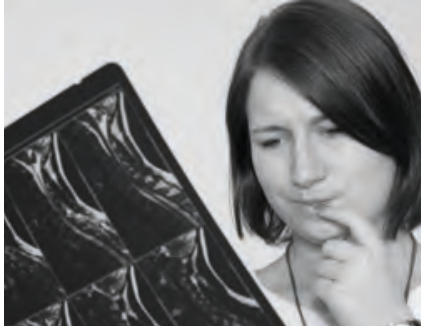

Lena Schulze

war das erste Mal in der Radiologie mit neun Jahren - zum Röntgen nach einem Skiunfall. Zur Recherche für den Facharztcheck traute sie sich jetzt wieder zu den Bildspezialisten. Dabei durfte sie sogar ein CT von innen kennenlernen und war froh, dieses Mal kein Patient zu sein (S. 22).

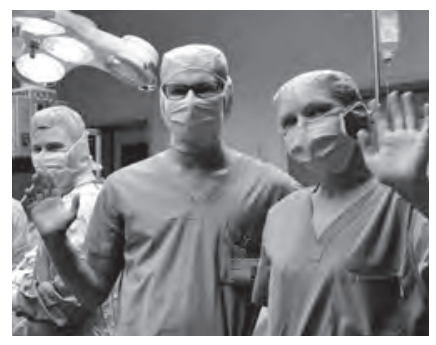

Dr. Julia Holler und Florian Hecker

haben sich der Chirurgie verschrieben - und entsprechend findet man die beiden auch sehr häufig am OP-Tisch. Für einen Artikel für Via medici bekamen wir den PJ-Student und die Oberärztin aus Gießen an den Schreibtisch! Sie erläutern uns die Therapie bei rupturiertem Aortenaneurysma (S. 34).

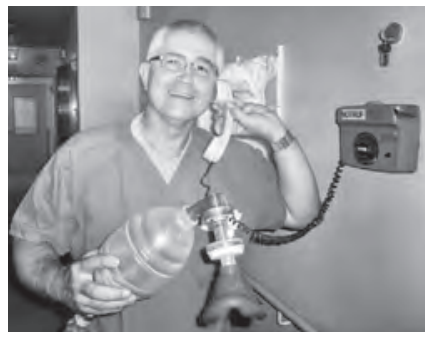

Dr. Horst Gross

ist Anästhesist und Intensivmediziner aus Berlin. Invasive Maßnahmen gehören zu seinem Beruf. Aus der täglichen Praxis weiß er, dass es gerade bei Punktionen oft Kniffe gibt, die in keinem Lehrbuch stehen. So wie etwa bei der Aszitespunktion (S. 40). 